\title{
Kraft lignin and silica as precursors of advanced composite materials and electroactive blends
}

\author{
Teofil Jesionowski • Lukasz Klapiszewski • \\ Grzegorz Milczarek
}

Received: 4 September 2013/Accepted: 10 October 2013/Published online: 23 October 2013

(C) The Author(s) 2013. This article is published with open access at Springerlink.com

\begin{abstract}
In this study, advanced multifunctional silica/ lignin composite materials have been prepared. The main focus of this study includes the chemical modification of Kraft lignin, and its interaction with silica matrix, thereby providing the possibility of applying the obtained systems in a number of areas, including electrochemistry. Analysis of dispersive-morphological properties revealed that the samples containing 10-20 parts by weight of lignin had the best parameters. The elemental analysis of the final composites, thus, obtained indicated an increase in the contents of carbon, hydrogen and sulphur with increasing quantity of lignin used. Spectrophotometric evaluation of the products obtained, proves the successful synthesis of silica/ lignin composites which is manifested by the presence of characteristic bands of appropriate functional groups. The increasing intensity of these bands with increasing content of lignin in the silica matrix conforms entirely with the expectations. Thus, obtained composite powders were blended with multiwalled carbon nanotubes at the mass ratio of 1:2 with the aid of ultrasound. The blends were cast-deposited on glassy carbon electrode and the electrochemical activity was assessed by cyclic voltammetry. It revealed the presence of a redox system assigned to ligninderived quinone/hydroquinone couple.
\end{abstract}

\section{T. Jesionowski $(\bowtie) \cdot$ Ł. Klapiszewski}

Institute of Chemical Technology and Engineering, Faculty of

Chemical Technology, Poznan University of Technology, M.

Sklodowskiej-Curie 2, 60965 Poznan, Poland

e-mail: teofil.jesionowski@put.poznan.pl

\section{G. Milczarek}

Institute of Chemistry and Technical Electrochemistry, Faculty of Chemical Technology, Poznan University of Technology, Piotrowo 3, 60965 Poznan, Poland

\section{Introduction}

The production of novel inorganic/organic composites with specific application possibilities has recently become a pressing need. The use of organic products of natural origin, including biomass in the broad sense of the word, is of particular interest [1]. A valuable and commonly used inorganic component of composites is silica. The successful combination of silica with a natural biopolymer, such as lignin, can provide new products with unique dispersive, morphological and physicochemical properties. To date, attempts at developing such systems have been made at several centres [2-7].

Many methods for the synthesis of silica have been proposed, including precipitation in polar or nonpolar media [8-11], hydrolysis and condensation of tetralkoxysilanes in an alcohol environment over a catalyst, most often a basic one [12-14], and the flame method [15]. High demand for silica and its widespread use are linked to its valuable physicochemical properties and highly developed surface area. An additional advantage is the potential for surface functionalisation to modify its chemical and physical character and extend the range of possible applications of the final products [16-18].

Lignin is a complex chemical compound most commonly derived from wood. It is one of the most abundant organic polymers on Earth, exceeded only by cellulose, binding $30 \%$ of non-fossil organic carbon and constituting from a quarter to a third of the dry mass of wood [19]. Different types of lignin have been described depending on the means of isolation [20-24]. From the chemical point of view, the parent lignin is an amorphous, polyphenolic material arising from an enzyme-mediated dehydrogenative polymerisation of three phenylpropanoid monomers: coumaryl, coniferyl and sinapyl alcohols [25-28]. The 
copolymer, thus, formed consists of substituted $\mathrm{C}_{9}$ units (6 aromatic and 3 propene carbons) interconnected by $\mathrm{C}-\mathrm{O}$ (mostly etheric) or C-C bonds [29].

The main challenge to the widespread use of lignin is to understand its complex structure and physicochemical properties. Lignin is more reactive than cellulose and other natural polymers, due to the presence of specific functional groups. Studies conducted on the reactivity of functional groups of the biopolymer, as well as its modification, have facilitated a succession of new methods of application in various industries.

Even though silica and lignins are electrically nonconducting, they have found applications in electrochemical sensors, as layers capable of pre-concentrating certain analytes in the vicinity of the electrode surface [30, 31]. Moreover, the biocompatibility and the easy chemical functionalisation of silica and silica-like thin films formed by sol-gel approaches have led to the use of such compounds as enzyme-grafting supports in electrochemical biosensors [32]. Similarly, lignins coming from various pulping processes have been shown to be applicable in electrochemical sensors owing to their residual quinone moieties, which are redox- and thus electroactive [33, 34]. In order to intensify the chemical properties of lignins that make it suitable for electrochemical applications, various methods of combining these materials with electronic conductors (carbon nanotubes or conducting polymers) have been proposed [1, 35, 36].

In this paper, we show that simple ultrasound-assisted blending of $\mathrm{KL}-\mathrm{SiO}_{2}$ composite with carbon nanotubes leads to a ternary composite displaying appreciable electrochemical activity and therefore potentially applicable in the preparation of electrochemical (bio)sensors.

\section{Experimental}

Silica precipitation in emulsion medium

In order to precipitate silica in an emulsion system two types of emulsion were prepared, an alkaline one (E1) and an acidic one (E2). The alkaline emulsion (E1) contained $200 \mathrm{~cm}^{3}$ of a $20 \%$ solution of sodium silicate (analytical grade), made by Vitrosilicon SA (Poland) to which a mixture of non-ionic emulsifiers (nonylphenylpolyoxy ethyleneglycol ethers: $2.6 \mathrm{~g}$ NP3 and $2.6 \mathrm{~g}$ NP6) and $300 \mathrm{~cm}^{3}$ of cyclohexane (analytical grade), made by Chempur (Poland) was introduced in portions. Then the emulsion components were subjected to homogenisation. The acidic emulsion E2 contained $280 \mathrm{~cm}^{3}$ of the organic phase and a mixture of emulsifiers: $1.0 \mathrm{~g} \mathrm{NP} 3$ and $1.8 \mathrm{~g}$ NP6. The mixture was dosed in portions to $264 \mathrm{~cm}^{3}$ of $5 \%$ hydrochloric acid (analytical grade) made by Chempur. The components of E2 were homogenised for about $15 \mathrm{~min}$. At the next step, the alkaline emulsion E1 was dosed into the acidic emulsion E2. After combination of the emulsions the system was destabilised at $85^{\circ} \mathrm{C}$, and then cyclohexane was separated by distillation. The sample was filtered off under reduced pressure, washed carefully with distilled water and methanol (analytical grade, Chempur). The precipitate obtained was dried in a convection drier at $105^{\circ} \mathrm{C}$ for $24 \mathrm{~h}$.

\section{Synthesis of composites}

Prior to the synthesis of silica/lignin composites, the silica surface was modified with $\mathrm{N}$-2-(aminoethyl)-3-aminopropyltrimethoxysilane (Sigma-Aldrich). An appropriate amount of the modifying agent was hydrolysed in a methanol:water system $(4: 1, \mathrm{v} / \mathrm{v})$ and then applied on the silica surface by the method previously described [11, 37]. At the next step two solutions were prepared. One of them was Kraft lignin (Sigma-Aldrich) dissolved in a mixture of dioxane:water $(9: 1, \mathrm{v} / \mathrm{v})$, while the other one was a water solution of sodium periodate (Sigma-Aldrich). The water solution of sodium periodate (solution 2) was dosed with a peristaltic pump into the solution of Kraft lignin (solution 1). The process was performed in the dark. After combination of the two solutions an appropriate amount of silica, previously modified with aminosilane, was added and the whole content was stirred for about $1 \mathrm{~h}$. After that time the solvent was evaporated in a vacuum evaporator and the final product was dried at $105^{\circ} \mathrm{C}$ in a stationary drier for $24 \mathrm{~h}$.

Physicochemical and dispersive-morphological properties of silica/lignin composites

The products were subjected to thorough analysis to establish their physicochemical and dispersive-morphological properties. The particle size distributions were determined with the use of a Zetasizer Nano ZS (0.6-6000 nm) and Mastersizer $2000(0.2-2000 \mu \mathrm{m})$, both made by Malvern Instruments Ltd. (UK), employing the methods of dynamic light scattering (DLS) and laser diffraction, respectively. Dynamic light scattering is a non-invasive, well-established technique for measuring the size and size distribution of molecules and particles typically in the submicron region, and with the latest technology even lower than $1 \mathrm{~nm}$. Typical applications of DLS are the characterisation of particles, which have been dispersed or dissolved in a liquid. The Brownian motion of particles or molecules in suspension causes laser light to be scattered different intensities. Analysis of these intensity fluctuations yields the velocity of the Brownian motion; and hence, the diameter of particle size $d$ (in $\mathrm{nm}$ ) using the Stokes-Einstein relationship. In turn, the laser diffraction method is based on two physical 
phenomena: diffraction and interference of light waves. In laser diffractometers, the component waves have the same amplitudes and depending on the angle of intersection the resultant wave is alternately quenched or enhanced, which is observed as a series of alternate bright and dark lines. The results are obtained as a relation between the volume $V$ (in $\%$ ) and the diameter of particles $d$ (in $\mu \mathrm{m}$ ), in fact of a fraction of particles. The limiting diameters of particle fractions are the equivalent diameters of the spherical balls, which would give the same diffraction pattern as the sample studied. The control unit (a PC) converts the pulses recorded into the diameters of particles, which is performed according to the MIE theory. This method assumes that the particles are spheres and are arranged randomly in the suspension, and that there is no interaction between them and there is no shielding of smaller particles by larger ones. The surface morphology and microstructure of the silica/lignin products were examined on the basis of the SEM images recorded from an EVO40 scanning electron microscope (Zeiss, Germany). Before testing, the samples were coated with Au for a time of 5 s using a Balzers PV205P coater.

Colorimetric analyses of the samples were made using the CIE $L * a * b *$ system and a Specbos 4000 spectrophotometer, made by Technische Instrumente $\mathrm{GmbH}$ (Germany). During measurement the head of the spectrophotometer was moved perpendicularly to the precisely formed tablet to a very short distance. CIE $L * a * b *$ is the most complete colour space specified by the International Commission on Illumination. The CIE $L * a * b *$ system describes and orders colours based on the opponent theory of colour vision. The opponent theory is that colours cannot be perceived as both red and green at the same time, or yellow and blue at the same time. However, a colour can be perceived as a combination of: red and yellow, red and blue, green and yellow, or green and blue. In the CIE $L * a * b *$ colour space, the colour coordinates in this rectangular coordinate system are:

$L^{*}$ _the lightness of the colour $\left(L^{*}=0\right.$ yields black and $L^{*}=100$ yields white),

$a^{*}$ - the red/green coordinate, with $+a^{*}$ indicating red, and $-a^{*}$ indicating green,

$b^{*}$ - the yellow/blue coordinate, with $+b^{*}$ indicating yellow, and $-b *$ indicating blue.

CIE $L * a * b *$ colour difference, between any two colours in CIE colour space, is the distance between the colour locations. This distance is typically expressed as $d E$ parameter.

To verify the process of synthesis of the biocomposites the presence of characteristic functional groups was verified by FT-IR spectroscopy on an IFS 66v/S spectrometer made by Bruker (Germany). Here, the materials were analysed in the form of tablets, made by pressing a mixture of anhydrous $\mathrm{KBr}$ (ca. $0.1 \mathrm{~g}$ ) and $1 \mathrm{mg}$ of the tested substance in a special steel ring under a pressure of $\sim 10 \mathrm{MPa}$.
The investigation was performed over a wavenumber range of $4000-400 \mathrm{~cm}^{-1}$ at a resolution of $0.5 \mathrm{~cm}^{-1}$.

Elemental composition of the products was established with the use of Vario El Cube instrument made by Elementar Analysensysteme (Germany), which gave the percentage contents of carbon, hydrogen, nitrogen and sulphur after high-temperature combustion of the samples analysed.

Preparation of $\mathrm{CNTs} / \mathrm{KL}-\mathrm{SiO}_{2}$ blends

Multiwalled carbon nanotubes (CNTs, diameter 6-9 nm, length $\sim 5 \mathrm{~mm}$ ) were purchased (from Sigma-Aldrich) and purified before use with $\mathrm{HNO}_{3}$ to remove amorphous carbon impurities and traces of catalysts, and with HF to remove inorganic impurities such as silica. Dimethylsulphoxide was obtained from Fluka (Germany) and was used as purchased. A concentrated aqueous ammonia solution was obtained from POCh (Poland) and was dissolved with deionised water to the desired concentration (see above). Analytical reagent grade potassium phosphates were used to prepare aqueous buffer ( $\mathrm{pH}$ 7.4) used as the supporting electrolyte in electrochemical measurements.

A quantity of $15 \mathrm{mg}$ of the purified CNTs and $7.5 \mathrm{mg}$ of the $\mathrm{KL}-\mathrm{SiO}_{2}$ composite were suspended in $4 \mathrm{~cm}^{3}$ of DMSO containing $100 \mu \mathrm{l}$ of $0.5 \mathrm{M} \mathrm{NH}_{3}(\mathrm{aq})$, and the suspension was vigorously homogenised with the aid of ultrasound for $30 \mathrm{~min}$. Immediately after the suspension was removed from the ultrasound field, its aliquot $(5 \mu \mathrm{l})$ was placed on the active surface of a glassy carbon electrode ( $2 \mathrm{~mm}$ in diameter) and the drop was allowed to dry out in an oven at $80^{\circ} \mathrm{C}$.

\section{Electrochemical characterisation}

Electrochemical experiments were carried out using an Autolab (PGSTAT-30) electrochemical analyser (EcoChemie, Netherlands) connected to a PC for control, data acquisition and storage. A standard three-electrode configuration was incorporated into a glass cell (volume $20 \mathrm{~cm}^{3}$ ). The working electrode was glassy carbon and the counter electrode was platinum wire. All potentials reported in this paper are referenced to an $\mathrm{Ag} / \mathrm{AgCl}(3 \mathrm{M} \mathrm{NaCl})$ electrode, neglecting the liquid junction potential.

\section{Results and discussion}

\section{Dispersive and morphological properties}

The silica/lignin composites obtained first underwent particle size determination. The microstructure and morphology of the samples were analysed on the basis of SEM 
Table 1 Dispersive characteristic of unmodified silica (sample 1), silica modified with aminosilane (sample 2) and silica/lignin composites (samples 3-9)

\begin{tabular}{|c|c|c|c|c|c|c|}
\hline \multirow[t]{3}{*}{ Sample no. } & \multirow{3}{*}{$\begin{array}{l}\text { Parts by weight of lignin per } 100 \text { parts } \\
\text { of silica matrix modified with aminosilane }\end{array}$} & \multicolumn{5}{|l|}{ Dispersive properties } \\
\hline & & \multirow[t]{2}{*}{$d(\mathrm{~nm})$ from Zetasizer Nano ZS } & \multicolumn{4}{|c|}{$d(\mu \mathrm{m})$ from Mastersizer 2000} \\
\hline & & & $d(0.1)$ & $d(0.5)$ & $d(0.9)$ & $d(4.3)$ \\
\hline 1 & 0 (Unmodified silica) & $\begin{array}{c}122-220 \\
2300-5560\end{array}$ & 4.1 & 17.3 & 39.8 & 19.9 \\
\hline 2 & 0 (Silica modified with aminosilane) & $\begin{array}{c}79-122 \\
295-459 \\
1110-3580\end{array}$ & 4.7 & 19.8 & 40.4 & 21.7 \\
\hline 3 & 3 & $\begin{array}{c}79-106 \\
1280-4150\end{array}$ & 4.1 & 16.1 & 39.2 & 19.4 \\
\hline 4 & 5 & $\begin{array}{c}68-122 \\
1100-3580\end{array}$ & 4.4 & 16.4 & 41.2 & 20.4 \\
\hline 5 & 10 & $\begin{array}{c}78-142 \\
955-4150\end{array}$ & 4.2 & 22.1 & 50.4 & 25.5 \\
\hline 6 & 20 & $\begin{array}{c}79-106 \\
955-4800\end{array}$ & 4.5 & 22.6 & 54.7 & 26.6 \\
\hline 7 & 30 & $\begin{array}{c}79-164 \\
955-4150\end{array}$ & 5.3 & 25.2 & 52.5 & 27.5 \\
\hline 8 & 40 & $\begin{array}{c}91-142 \\
1110-4800\end{array}$ & 6.4 & 27.3 & 55.6 & 29.7 \\
\hline 9 & 50 & $\begin{array}{c}79-142 \\
825-4150\end{array}$ & 6.8 & 28.1 & 56.3 & 30.4 \\
\hline
\end{tabular}

$d$ the diameter of particles

images. Results of the dispersive and morphological analyses of silica, both unmodified and modified with aminosilane, and Kraft lignin are presented in Table 1.

The particle size distribution of silica precipitated in the emulsion system described above shows two bands, in the ranges $122-220$ and $2300-5560 \mathrm{~nm}$. It is non-homogeneous to some degree, as indicated by the appearance of larger clusters of secondary agglomerates [10]. This conclusion is supported by SEM image analysis (Fig. 1a), also showing that the silica particles have regular and uniform shapes $[8,11]$. According to the data provided by the Mastersizer 2000, $50 \%$ by volume of unmodified silica is occupied by particles of diameters smaller than $17.3 \mu \mathrm{m}$, while $90 \%$ of the sample volume is taken up by particles of diameters smaller than $39.8 \mu \mathrm{m}$.

The preliminary functionalisation of silica with aminosilane resulted in the activation of the silica surface, but did not cause appreciable changes in the dispersive-morphological properties. The particle size distribution of silica modified with aminosilane revealed that besides primary particles of diameters up to $100 \mathrm{~nm}$, there are clusters of aggregates $(295-459 \mathrm{~nm})$ and agglomerates $(1110-3580 \mathrm{~nm})$. The data provided by the Mastersizer 2000 confirmed that sample 2 (silica modified with aminosilane) showed a tendency to agglomeration. The silica/lignin composites were analysed in sequence, ordered by increasing content of lignin. With increasing content of lignin by weight, the samples were found to contain particles with increasing diameters and an increasing tendency towards formation of secondary agglomerates. These observations are best illustrated by the particle size distributions according to volume contribution (Fig. 2). Additional confirmation of the above observations is provided by analysis of the relevant SEM images (Figs. 1c, d).

The above SEM images also show that surface functionalisation of silica with Kraft lignin did not change the uniform shape of the silica particles. The appearance of larger particles in silica/lignin composites can be explained by the type of silica precipitated and the fact that the Kraft lignin used had a wide distribution of particle sizes. According to Zetasizer Nano ZS measurements, the particle size distribution of lignin has three characteristic bands covering the diameter ranges 220-459, 712-2670 and $3580-5560 \mathrm{~nm}$. Analysis of dispersive-morphological 

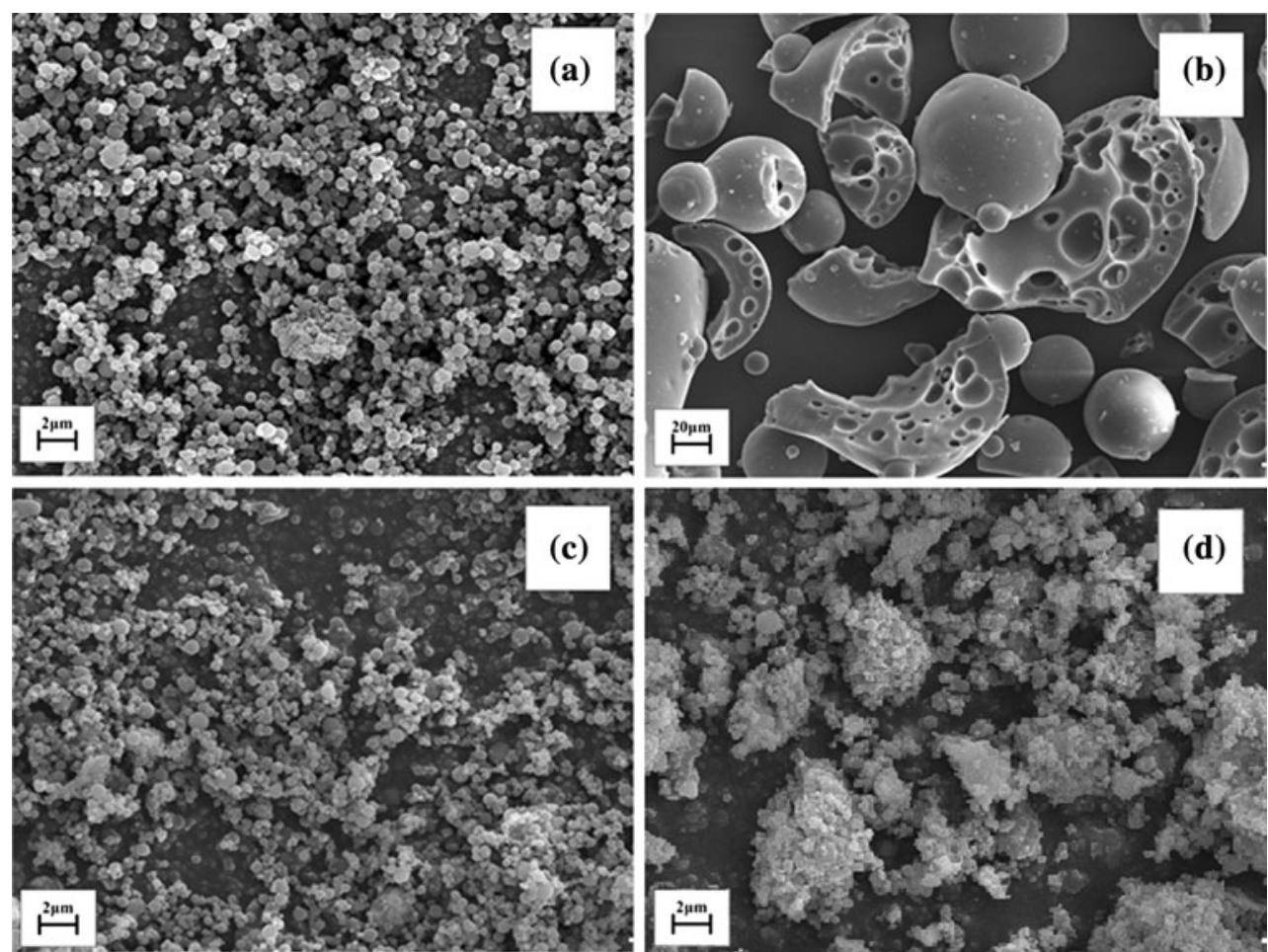

Fig. 1 SEM images of unmodified silica (a), Kraft lignin (b), composite containing 10 parts by weight of lignin per 100 parts of silica (c), composite containing 40 parts by weight of lignin per 100 parts of silica (d)

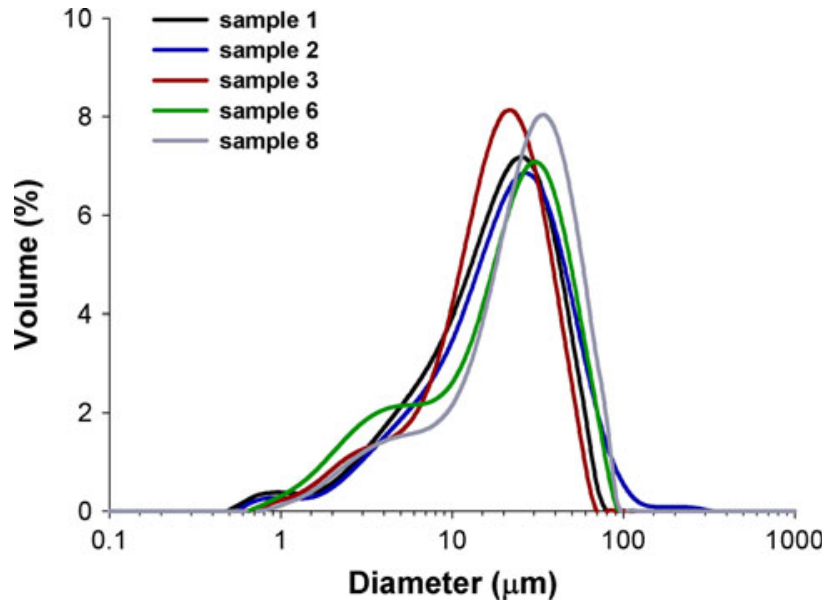

Fig. 2 Particle size distributions (Mastersizer 2000) of unmodified silica, silica modified with aminosilane and selected composites

properties revealed that the samples containing 10-20 parts by weight of lignin had the best parameters.

Elemental analysis

Table 2 presents the elemental contents of carbon, hydrogen, nitrogen and sulphur in unmodified silica (sample 1), in silica preliminarily modified with aminosilane (sample 2), and in silica/lignin composites (samples 3-9).
Table 2 Chemical content of unmodified silica, silica modified with aminosilane and silica/lignin composites on the basis of silica modified with aminosilane

\begin{tabular}{lllll}
\hline Sample no. & \multicolumn{4}{l}{ Elemental content $(\%)$} \\
\cline { 2 - 5 } & $\mathrm{N}$ & $\mathrm{C}$ & $\mathrm{H}$ & $\mathrm{S}$ \\
\hline 1 & - & 0.62 & 0.89 & - \\
2 & 0.57 & 2.87 & 2.02 & - \\
3 & 0.41 & 5.01 & 2.19 & 0.16 \\
4 & 0.38 & 6.36 & 2.26 & 0.25 \\
5 & 0.37 & 7.12 & 2.29 & 0.38 \\
6 & 0.33 & 8.20 & 2.31 & 0.54 \\
7 & 0.32 & 10.32 & 2.32 & 0.71 \\
8 & 0.30 & 11.74 & 2.36 & 0.83 \\
9 & 0.29 & 13.05 & 2.39 & 1.05 \\
\hline
\end{tabular}

The results of the elemental analysis are as expected; only the contents of carbon and hydrogen are slightly higher than expected, which is most probably a consequence of the use of cyclohexane as a solvent. Preliminary modification of silica with aminosilane caused an increase in nitrogen content to $0.57 \%$ and a slight increase in the contents of carbon and hydrogen, which is understandable as the aminosilane used contains these elements. This result confirms the success of the preliminary modification and a 
Table 3 Colorimetric data of unmodified and aminosilane-grafted silicas and silica/lignin composites

\begin{tabular}{llrrr}
\hline Sample no. & \multicolumn{4}{l}{ Colorimetric data } \\
\cline { 2 - 5 } & $L^{*}$ & \multicolumn{1}{c}{$a^{*}$} & \multicolumn{1}{c}{$b^{*}$} & $\mathrm{~d} E$ \\
\hline 1 & 93.78 & 0.24 & 2.55 & - \\
2 & 92.83 & 0.26 & 2.63 & 1.03 \\
3 & 86.50 & 4.90 & 26.93 & 25.86 \\
4 & 81.18 & 6.36 & 27.63 & 28.61 \\
5 & 74.79 & 6.69 & 23.10 & 28.84 \\
6 & 70.98 & 6.75 & 21.83 & 30.55 \\
7 & 63.82 & 9.41 & 19.06 & 35.41 \\
8 & 57.31 & 10.43 & 18.47 & 41.07 \\
9 & 51.27 & 11.38 & 15.70 & 45.87 \\
\hline
\end{tabular}

$L^{*}$ the lightness of the colour, $a^{*}$ the red/green coordinate, with $+a^{*}$ indicating red and $-a^{*}$ indicating green, $b^{*}$ the yellow/blue coordinate, with $+b^{*}$ indicating yellow and $-b^{*}$ indicating blue, $d E$ total colour difference

resulting increase in the surface activity of the silica. Lignin was preliminarily subjected to oxidation with sodium periodate to activate its functional groups and facilitate binding to the amine groups on the silica surface. The elemental analysis of the final biocomposites, thus, obtained indicated an increase in the contents of carbon, hydrogen and sulphur with increasing quantity of lignin used. The presence of small sulphur content is related to the presence of this element in the Kraft lignin used for the study.

\section{Colorimetric analysis}

The unmodified silica (sample 1) used as a reference sample has high lightness, described by an $L^{*}$ value of 93.8. Modification with aminosilane (sample 2) did not cause a significant change in this parameter value. A considerable and systematic decrease in $L^{*}$ was observed for silica/lignin composites with increasing content by weight of lignin (Table 3).

For the composite containing 3 parts by weight of lignin (sample 3) the value of $L^{*}$ was 87.5 , and for the sample containing 50 parts by weight of lignin (sample 9) the value of $L^{*}$ decreased to 45.3. These pronounced changes in lightness confirm successful surface functionalisation. Another colorimetric parameter observed to change was $d E$, describing the total change in colour. For sample 3, the value of $d E$ was 25.9, while for sample 9 it was 45.9 ; hence, it systematically increased with increasing content of lignin in the composites. The parameters $a^{*}$ and $b^{*}$ describing the contribution of particular colours (in the CIE $L^{*} a^{*} b^{*}$ system) undergo only small changes, indicating a small increase in the contribution of red $\left(a^{*}\right)$ and a decrease in the contribution of yellow $\left(b^{*}\right)$.
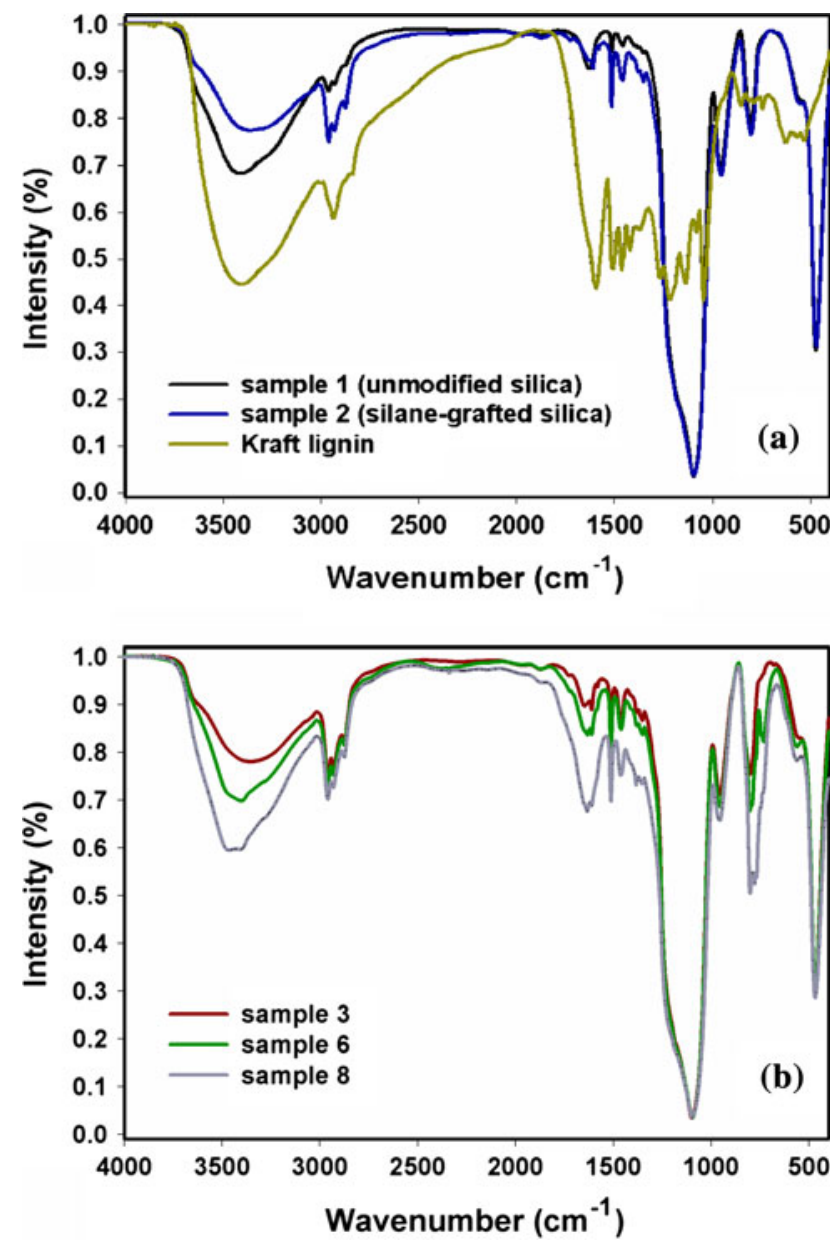

Fig. 3 FT-IR spectra of unmodified silica, silica modified with aminosilane and Kraft lignin a, and three selected composites b

\section{Characterisation of functional groups}

The presence of certain functional groups in the samples studied was inferred on the basis of the FT-IR spectra. Figure 3a presents the FT-IR spectra of unmodified silica, silica modified with aminosilane ( $N$-2-(aminoethyl)-3aminopropyltrimethoxysilane), and pure Kraft lignin. Figure $3 \mathrm{~b}$ gives the FT-IR spectra of silica/lignin biocomposites containing 3,20 and 40 parts by weight of lignin per 100 parts of $\mathrm{SiO}_{2}$ modified with aminosilane.

The spectrum of unmodified silica shows a broad band in the range $3600-3200 \mathrm{~cm}^{-1}$, attributed to stretching vibrations of $\mathrm{O}-\mathrm{H}$, in this sample typical of physically bound water. The presence of water is additionally evidenced by the band at $1631 \mathrm{~cm}^{-1}$. The other bands observed correspond to typical vibrations of silica, $\mathrm{Si}-\mathrm{O}-\mathrm{Si}\left(v_{\mathrm{s}}: 1096 \mathrm{~cm}^{-1}, v_{\mathrm{as}}\right.$ : $\left.805 \mathrm{~cm}^{-1}\right), \mathrm{Si}-\mathrm{OH}\left(v_{\mathrm{s}}: 960 \mathrm{~cm}^{-1}\right)$ and $\mathrm{Si}-\mathrm{O}\left(\delta: 470 \mathrm{~cm}^{-1}\right)$, where $v_{\mathrm{s}}$ and $v_{\text {as }}$ denote symmetric and asymmetric stretching vibrations and $\delta$ denotes bending vibrations [38]. A lowintensity band in the range $2965-2850 \mathrm{~cm}^{-1}$ can be attributed to stretching vibrations of $\mathrm{C}-\mathrm{H}$, which most probably 


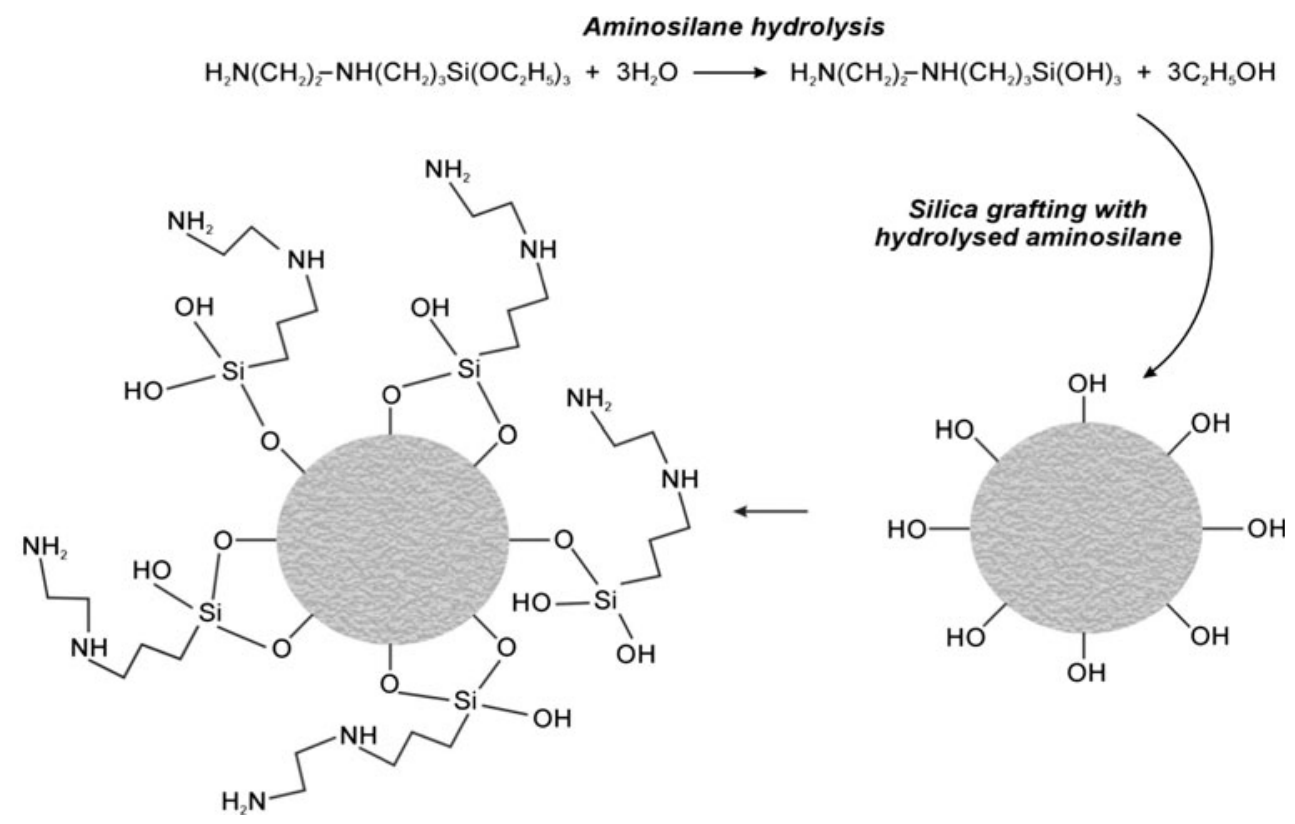

Scheme 1 Mechanism of silica modification with aminosilane

come from the solvent. As a result of modification with aminosilane the intensity of the band corresponding to stretching vibrations of $\mathrm{C}-\mathrm{H}$ increased. The band in the range $3600-3200 \mathrm{~cm}^{-1}$ was slightly broadened, which indicates the overlapping of two bands corresponding to the stretching vibrations of $\mathrm{O}-\mathrm{H}$ and $\mathrm{N}-\mathrm{H}$, from the modifier. The appearance of a low-intensity band at $1650-1560 \mathrm{~cm}^{-1}$, attributed to the bending vibration of $\mathrm{N}-\mathrm{H}$, confirms the success of surface modification with aminosilane.

The FT-IR spectrum of Kraft lignin [39, 40] (Fig. 3a) shows the following bands: $\mathrm{O}-\mathrm{H}$ stretching vibrations (phenolic $-\mathrm{OH}$ and aliphatic $-\mathrm{OH}$ ) in the range $3600-3200 \mathrm{~cm}^{-1}$, and $\mathrm{C}-\mathrm{H}$ stretching vibrations in the range $2960-2920 \mathrm{~cm}^{-1}\left(\mathrm{CH}_{3}+\mathrm{CH}_{2}\right)$ and $2850-2840 \mathrm{~cm}^{-1}$ $\left(\mathrm{OCH}_{3}\right)$. A broad band in the range $1710-1550 \mathrm{~cm}^{-1}$ corresponds to overlapping of the stretching vibrations of nonconjugated and conjugated group bonds $\mathrm{C}=\mathrm{O}$ and the stretching vibrations of $\mathrm{C}-\mathrm{C}$ of the aromatic skeleton at 1600,1510 and $1420 \mathrm{~cm}^{-1}$. In the same spectrum of lignin there are also bands at 1375,1265 and $1220 \mathrm{~cm}^{-1}$, attributed to stretching vibrations of $\mathrm{C}-\mathrm{O}, \mathrm{C}-\mathrm{O}(\mathrm{H})+\mathrm{C}-\mathrm{O}(\mathrm{Ar})$ of phenol groups and ether bonds, which are an important type of bonds in lignin. The presence of the ether bonds $\mathrm{C}-\mathrm{O}-\mathrm{C}$ is also indicated by the band corresponding to the stretching vibrations at $1045 \mathrm{~cm}^{-1}$. The other bands characteristic of lignin are that corresponding to inplane deformation $\delta_{\text {ip }} \mathrm{Ar} \mathrm{C}-\mathrm{H}$ at $1140 \mathrm{~cm}^{-1}$ and out-of-plane deformation $\delta_{\text {op }} \mathrm{Ar} \mathrm{C}-\mathrm{H}$, appearing below $1000 \mathrm{~cm}^{-1}$, e.g. at 854,816 and $790 \mathrm{~cm}^{-1}$. Figure $3 \mathrm{~b}$ presents the FT-IR spectra of the silica/lignin biocomposites obtained, evidencing the successful production of silica/lignin composites manifested by the presence of bands characteristic of appropriate functional groups. The increasing intensity of these bands with increasing content of lignin in the silica matrix conforms entirely with the expectations. An important band appearing in the spectra of samples with high lignin content is that in the range $850-720 \mathrm{~cm}^{-1}$, whose presence can be attributed to stretching vibrations of the $\mathrm{Si}-\mathrm{C}$ bonds of the aminosilane used. Mechanism of silica modification with aminosilane is shown in Scheme 1; in turn, functionalisation of oxidised lignin with amino-modified silica is shown in Scheme 2.

Blend morphology

Figure 4 shows the morphology of parent CNTs and blends made of CNTs and silanised $\mathrm{SiO}_{2}$, and CNTs/KL-SiO blends with both unmodified and functionalised silica as studied by SEM imaging.

As can be seen, there are significant structural differences between the four studied samples. First of all, simple blending of CNTs with silica results only in a physical mixture of the two. The presence of KL seems to result in both a better dispersion of carbon CNTs and also in a better dispersion of silica spheres in the ternary composite. If additionally silica was amino-functionalised, the individual CNTs seem to be densely decorated with some sub-micron particles, most probably the smallest fraction of silica spheres.

\section{Electrochemical characterisation}

Since the composites investigated here are composed of two macromolecules (an inorganic and organic one) both showing pure electrochemical conductance, we blended them with CNTs-a well-known, very good electronic conductor. After depositing on a glassy carbon electrode, 
Scheme 2 Mechanism of oxidised lignin functionalisation with amino-modified silica

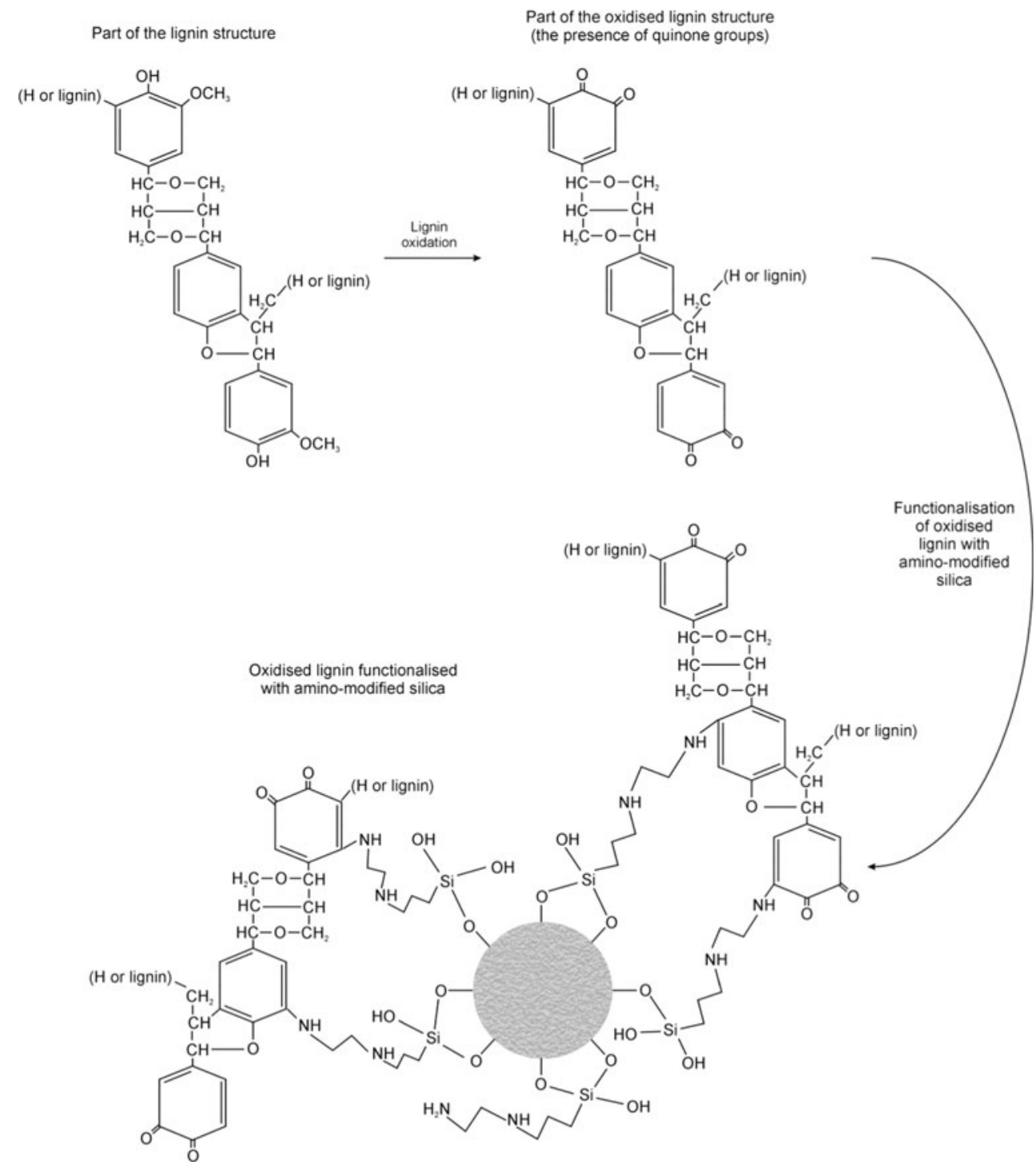

the activity of such a blend, in turn related to the electrochemical activity of the $\mathrm{KL}-\mathrm{SiO}_{2}$ composites, could be studied. Typical cyclic voltammograms of such blends recorded at three different scan rates are shown in Fig. 5 for compositions containing non-silanised silica and for compositions with amino-silanised silica.

As can be seen, all blends show scan-rate-dependent responses arising from the contribution of the double-layer charging of CNTs and lignin in the composite. For the composites based on unmodified silica we observed a nearly linear increase in the current responses to the content of lignin in the composite. We attribute this to a strong interaction of KL with CNTs [35], most probably bringing the nanotubes close to each other in spite of the silica particles, and thus generating a relatively high current response. It is noteworthy that with an increased amount of $\mathrm{KL}$ in the composite the cyclic voltammograms show a continuous increase in a reversible redox couple at the mean-peak potential of ca. $0.15 \mathrm{~V}$, which can be attributed to the lignin-derived quinone moieties [1, 33-36].

The silane-functionalised silica shows higher electrochemical activity after blending with CNTs, and the electroactivity also increases with the content of KL in the KL$\mathrm{SiO}_{2}$ composite; however, we observed the highest activity for the composite containing 20 parts by weight of KL (see current scales) and a decrease in overall capacitive currents. We believe that this is due to optimal ionic charge balance between protonated amine groups grafted on silica particles and negatively charged oxygen-containing groups in oxidised KL. As for silane-free silica, redox peaks attributable to residual quinones are also seen, and their magnitude is related to the content of $\mathrm{KL}$ in the composite.

The observed electrochemical activity of the $\mathrm{KL}-\mathrm{SiO}_{2}$ composite, especially that due to residual quinone moieties, 

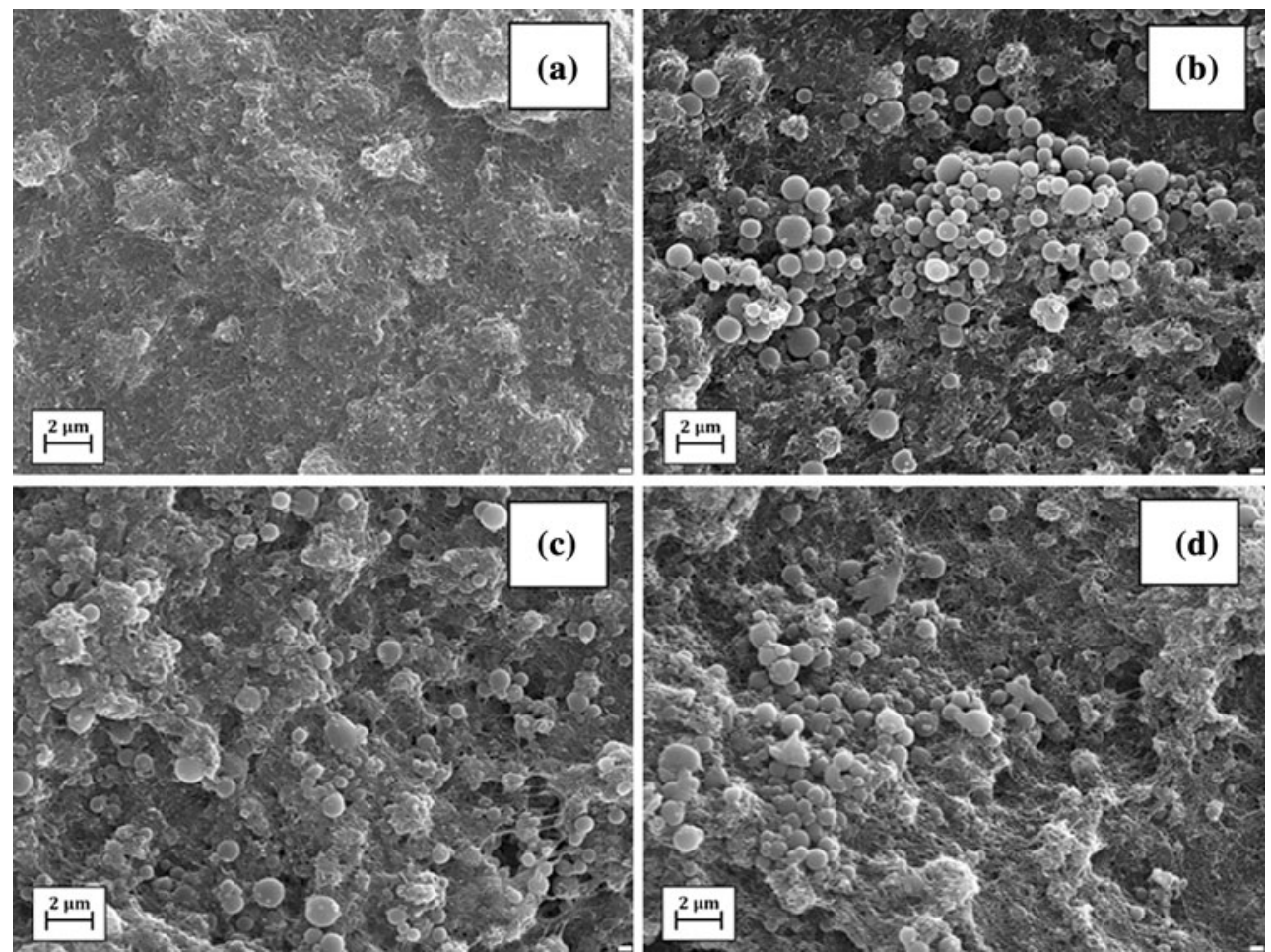

Fig. 4 SEM images of parent CNTs (a), CNTs blended with silica (b), CNTs blended with unmodified $\mathrm{SiO}_{2}$ and silane-functionalised silica modified with 20 parts by weight of $\operatorname{Kraft} \operatorname{lignin}(\mathbf{c}, \mathbf{d})$
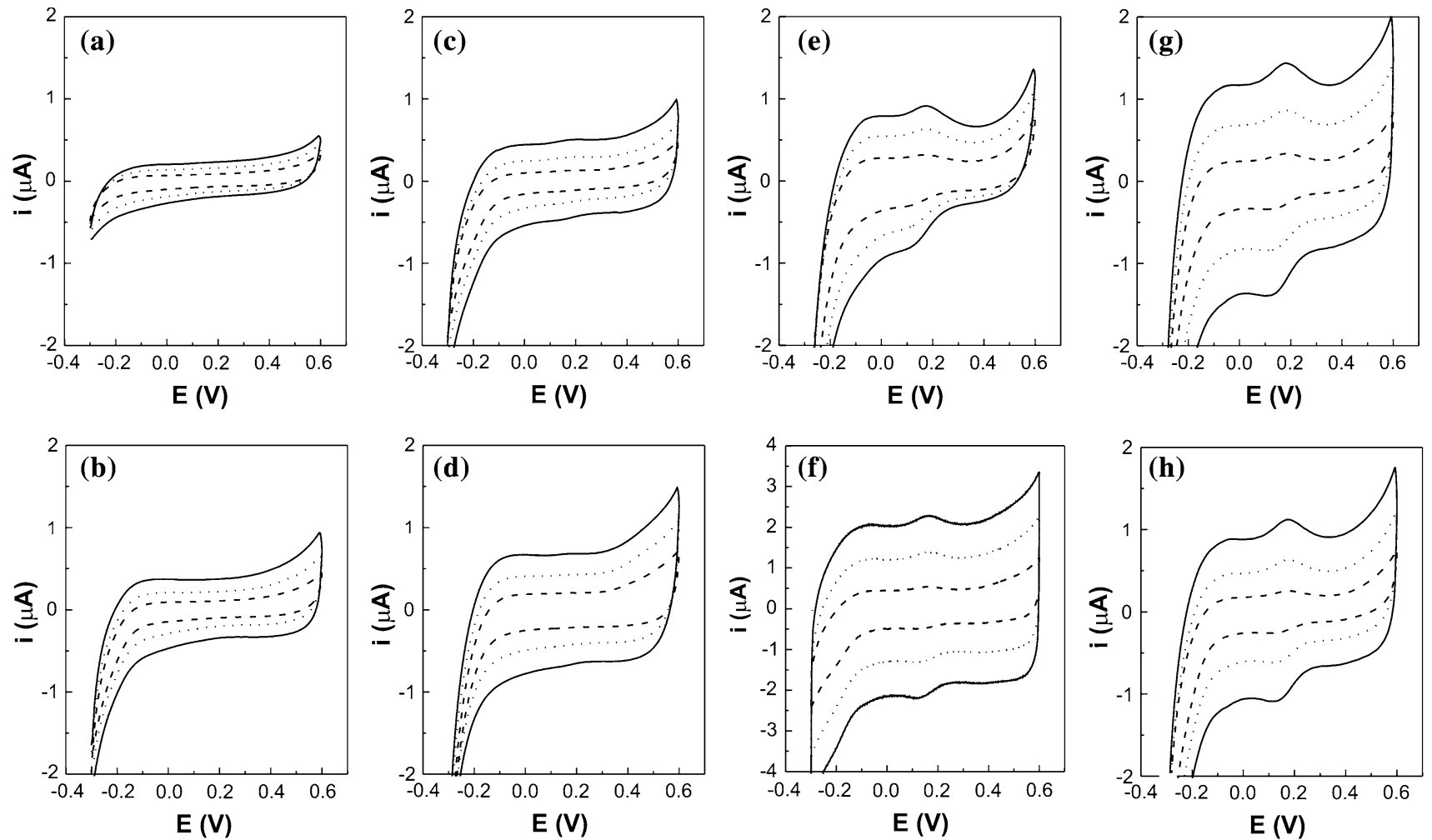

Fig. 5 Cyclic voltammograms recorded at 20 (dashed line), 40 (dotted line) and $60 \mathrm{mV} \mathrm{s}^{-1}$ (solid line) for CNTs blended with parent silica (a), silane-functionalised silica (b), silica and silanegrafted silica modified with 3 parts by weight of $\operatorname{KL}(\mathbf{c}, \mathbf{d})$, silica and

silane-functionalised silica modified with 20 parts by weight of KL (e, f), silica and silane-modified silica grafted with 40 parts by weight of $\mathrm{KL}(\mathbf{g}, \mathbf{h})$ 
point to the possibility of the application of such materials in electrochemical sensors for such applications as previously proposed [33, 34, 36].

Assuming that the reversible redox transition is entirely due to a 2-electron/2-proton reaction of quinone reduction/ oxidation and on the basis of redox peak area and the mass of the blend deposited on electrode one may estimate the density of redox sites in the blend, which is around $0.5 \mathrm{mmol} / \mathrm{g}$ for the composites with the highest $\mathrm{KL}$ content.

\section{Conclusions}

A chemical connection of silica, obtained in nonpolar medium, and Kraft lignin has been performed. Preliminary silica surface modification with aminosilane, and chemical activation of lignin had impact on type of interactions between the precursors. Effectiveness of synthesis methodology has been confirmed by spectrophotometric analysis. Throughout the research, an optimal lignin content in silica matrix has been determined, allowing for obtaining most advantageous dispersive-morphological properties (10-20 weight parts of lignin per 100 weight parts of silica). Blending the $\mathrm{KL}-\mathrm{SiO}_{2}$ composites with carbon nanotubes as electronic conductor allows for exploring the electrochemical activity of these materials and creates a high surface area three-dimensional deposit on flat electrodes that tentatively can be used as potential electrocatalytic transducing layers for various electrochemical sensors and biosensors. This expectation is justified by the well-known compatibility of silica with organic materials such as enzymes.

Acknowledgements This study was financially supported by the Poznan University of Technology research Grant No. 32-375/2013DS and by the Polish Ministry of Science and Higher Education under Project No. N209 450939.

Open Access This article is distributed under the terms of the Creative Commons Attribution License which permits any use, distribution, and reproduction in any medium, provided the original author(s) and the source are credited.

\section{References}

1. Milczarek G, Inganäs O (2012) Science $335: 1468$

2. Hayashi J, Shoji T, Watada Y, Muroyama K (1997) Langmuir 13:4185

3. Hasegawa I, Fujii Y, Yamada K, Kariya C, Takayama T (1999) J Appl Polym Sci 73:1321
4. Telysheva G, Dizhbite T, Jashina L, Andersone A, Volperts A, Ponomarenko J, Mironova-Ulmane N (2009) Bioresources 4: 1276

5. Qu Y, Tian Y, Zou B, Zhang J, Zheng Y, Wang L, Li Y, Rong C, Wang Z (2010) Bioresource Technol 101:8402

6. Kajiwara Y, Chujo Y (2011) Polym Bull 66:1039

7. Guigo N, Vincent L, Mija A, Naegele H, Sbirrazzuoli N (2009) Compos Sci Technol 69:1979

8. Jesionowski T (2001) Colloids Surf A 190:153

9. Żurawska J, Krysztafkiewicz A, Jesionowski T (2002) J Chem Technol Biotechnol 77:917

10. Jesionowski T (2006) Pigm Resin Technol 35:252

11. Jesionowski T, Ciesielczyk F, Krysztafkiewicz A (2010) Mater Chem Phys 119:65

12. Stöber W, Fink A, Bohn E (1968) J Colloid Interface Sci 26:62

13. Ibrahim IAM, Zikry AAF, Sharaf MA (2010) J Am Sci 6:985

14. Lin L, Zhang H, Cui H, Xu M, Cao S, Zheng G, Dong M (2013) Colloids Surf B 101:97

15. Wypych G (2010) Handbook of fillers. ChemTec Publishing, Toronto

16. Jesionowski T, Żurawska J, Krysztafkiewicz A (2003) Appl Surf Sci 205:212

17. Zamora P, Narváez A, Domínguez E (2009) Bioelectrochemistry $76: 100$

18. Dai ZH, Ni J, Huang XH, Lu GF, Bao JC (2007) Bioelectrochemistry $70: 250$

19. Boerjan W, Ralph J, Baucher M (2003) Annu Rev Plant Biol 54:519

20. Brauns FE (1939) J Am Chem Soc 61:2120

21. Monties B (1988) Method Enzymol 161:31

22. Wallberg O, Linde M, Jönsson AS (2006) Desalination 99:413

23. Penkina A, Hakola M, Paaver U, Vuorinen S, Kirsimäe K, Kogermann K, Veski P, Yliruusi J, Repo T, Heinämäki J (2012) Int J Biol Macromol 51:939

24. Li Z, Ge Y (2012) Int J Biol Macromol 51:1116

25. Lund H, Baizer HM (1991) Organic electrochemistry: an introduction and guide. Marcel Dekker, New York

26. Ralph J, Lundquist K, Brunow G, Lu F, Kim H, Schatz PF, Marita JM, Hatfield RD, Ralph SA, Christensen JH, Boerjan W (2004) Phytochem Rev 3:29

27. Collinson SR, Thielemans W (2010) Coordin Chem Rev 254: 1854

28. Micic M, Radotic K, Jeremic M, Djikanovic D, Kämmer ST (2004) Colloids Surf B 34:33

29. Donaldson LA (2001) Phytochemistry 57:859

30. Zhang T, Chai Y, Yuan R, Guo J (2012) Mater Sci Eng C 32:1179

31. Sun D, Xie X, Zhang H (2010) Colloids Surf B 75:88

32. Liang RP, Wang ZX, Zhang L, Qiu JD (2012) Sensor Actuat B 166:569

33. Milczarek G (2007) Electroanalysis 19:1411

34. Milczarek G (2009) Langmuir 25:10345

35. Milczarek G (2010) J Electroanal Chem 638:178

36. Milczarek G, Rebis T (2012) Int J Electrochem 130980:1

37. Jesionowski T, Krysztafkiewicz A (2000) J Non-Cryst Solids 277:45

38. Hou Z, Zhang C, Li C, Xu Z, Cheng Z, Li G, Wang W, Peng C, Lin J (2010) Eur J 16:14513

39. Tejado A, Peňa C, Labidi J, Echeverria JM, Mondragon I (2007) Bioresource Technol 98:1655

40. González Alriols M, Garcia A, Llano-ponte R, Labidi J (2010) Chem Eng J 157:113 